\title{
Use of low molecular mass heparin (enoxaparin) in newborn infants: a prospective cohort study of 62 patients
}

\author{
W Streif, G Goebel, A K C Chan, M P Massicotte
}

See end of article for authors' affiliations

Correspondence to: Dr Streif, Department of Pediatrics, University of Innsbruck, 6020 Innsbruck, Austria;

Werner.Streif@uibk.ac.at

Accepted

30 October 2002

\begin{abstract}
Objective: To detail low molecular mass heparin (enoxaparin) use in the first few months of life. Design: Prospective, consecutive cohort of unselected newborn infants.

Methods: Newborn infants were divided into groups by gestational age, underlying condition, hepatic and renal function, thrombocytopenia, and prothrombin time (PT/INR). Groups were analysed with respect to many aspects of enoxaparin treatment using multivariate methods.

Results: Sixty two newborn infants received enoxaparin representing 5.39 treatment years. Thromboembolic events (TEs) occurred predominantly in the lower and upper venous system in the presence of indwelling catheters (69\%). Preterm infants required longer than full term infants to achieve an anti-(factor $\mathrm{Xa}$ ) level in the target range (six versus two days). Preterm infants required higher doses of enoxaparin than full term infants to maintain anti-(factor $\mathrm{Xa}$ ) levels in the target range $(2.1 \vee 1.7$ $\mathrm{mg} / \mathrm{kg} / 12 \mathrm{~h}$ ). Infants with congenital heart disease (CHD) required less enoxaparin than those without CHD to maintain an anti-(factor $X a)$ level in the target range $(1.7 \vee 2.1 \mathrm{mg} / \mathrm{kg} / 12 \mathrm{~h})$. Impaired renal and liver function influenced the number of dose changes needed (three versus one a month). Complete or partial resolution of TE was accomplished in 59\% of newborn infants. Four infants developed major bleeds (1.2\% per patient year). Recurrent TE and clot extension occurred in three infants $10.9 \%$ per patient year).

Conclusions: Preterm infants are more difficult to treat with enoxaparin than full term infants. Enoxaparin appears to be an alternative to treatment with standard heparin or no treatment.
\end{abstract}

$\mathrm{T}$ hromboembolic events (TEs) are increasingly common secondary complications in newborn infants treated for serious primary disorders. ${ }^{1}$ Currently, newborn infants with TEs either receive supportive care alone or are treated according to guidelines extrapolated from adults. ${ }^{2}$ Optimal prevention and treatment of TEs in newborn infants probably differs from older children and adults because of important age dependent features of haemostasis that alter the pathophysiology of the thrombotic process and the response to antithrombotic treatment. ${ }^{34}$

Intravenous standard heparin is a widely used anticoagulant in newborn infants. ${ }^{25}$ Dose adjusted continuous intravenous standard heparin has been shown to extend the function of indwelling catheters, including umbilical catheters. $^{78}$ There is good evidence that intravenous standard heparin administered during and after cardiac catheterisation may decrease the risk of TE in infants with congenital heart disease (CHD). ${ }^{9}{ }^{10}$ Accelerated clearance of standard heparin, physiologically decreased plasma concentrations of antithrombin, and increased plasma concentrations of several acute phase proteins that bind to standard heparin may adversely affect the efficiency of standard heparin. Apart from the well known complication of bleeding, standard heparin can produce thrombocytopenia and osteoporosis in adults. ${ }^{11}{ }^{12}$

Subcutaneous injection of low molecular mass heparin (LMMH) has been shown to be as effective and safe as standard heparin in numerous trials in adults. ${ }^{13}$ LMMHs have high bioavailability because most heparin binding proteins do not bind to or neutralise them. Predictable pharmacokinetics allow minimal monitoring, which is critically important in infants with poor venous access. ${ }^{13}$ Data from the literature suggest that LMMHs are associated with a lower incidence of immune thrombocytopenia and osteoporosis in adults. ${ }^{13}$
A paediatric thromboembolism programme, which included an outpatient anticoagulation clinic, was initiated at the Hospital for Sick Children (HSC), Toronto, Canada in July 1991. The objectives were threefold: to establish consistent treatment programmes using the best available evidence; to develop a database of anticoagulation treatment in a large consecutive cohort of unselected children; to initiate clinical trials to investigate the efficacy and safety of antithrombotic drugs in the young. Dix et $a l^{14}$ reviewed the use of LMMH (enoxaparin) in nine newborn infants. Our study summarises the use of enoxaparin in 62 newborn infants. It extends the results of the previous report, as more data increased the power of the study allowing a more in depth statistical analysis, which includes the effect of gestational age, severity of the underlying condition defined by the need for intensive care and assisted ventilation, CHD, impaired renal and liver function, thrombocytopenia, and abnormal coagulation screening tests.

This study is the first to detail the complexity of enoxaparin management in preterm and full term newborn infants in the first few months of life.

\section{MATERIALS AND METHODS \\ Patient population}

Data were obtained on consecutive newborn infants less than 2 months of age referred to the pediatric thromboembolism program at the Hospital for Sick Children (HSC), Toronto,

Abbreviations: CHD, congenital heart disease; HSC, The Hospital For Sick Children, Toronto, Canada; INR, international normalised ratio; LMMH, low molecular mass heparin; TE, thromboembolic event; US, ultrasonography 
Canada between 1 January 1997 and 31 December 1998. All had underlying disorders and were referred to the anticoagulation service as inpatients either through the haematology consult service or directly through the thromboembolism program. The cohort represents all newborn infants treated with enoxaparin at HSC. All newborn infants received enoxaparin (Aventis Pharma, Laval, Quebec, Canada) during the study period. All infants were followed through an outpatient anticoagulation service for a minimum of three months after enoxaparin treatment was completed.

\section{Data collection}

All laboratory and clinical data were collected prospectively. Each infant was evaluated by a doctor at the initiation and completion of treatment and on a regular basis in between. The evaluation consisted of a standardised history, physical examination, and measurement of complete blood count and prothrombin time (PT)/international normalised ratio (INR), activated partial thromboplastin time, and plasma levels of anti-(factor Xa) (Stachrom Stago Diagnostics, Mississauga, Ontario, Canada). The following information was recorded: gestational age, sex, weight, need for intensive care/assisted ventilation, history of TE, underlying disorder, secondary disorders including impaired renal and liver function, surgery, presence of central venous lines, diet, and drugs. The following data were collected and analysed: initial dose, dose required to achieve and maintain target anti-(factor Xa) levels, time taken to achieve target anti-(factor Xa) range, all laboratory testing including anti-(factor Xa) tests, and dose changes. Bleeding and TEs were recorded.

\section{Monitoring and enoxaparin treatment Monitoring}

Enoxaparin was administered and monitored in all newborn infants using a modified standardised nomogram. ${ }^{15}$ Changes in enoxaparin doses were made by a doctor, or a nurse under medical supervision. Plasma levels of anti-(factor Xa) were measured at the HSC coagulation laboratory.

\section{Target anti-(factor $\mathrm{Xa}$ ) range and duration}

The therapeutic target anti-(factor Xa) range was 0.5-1.0 U/ml and $0.1-0.3 \mathrm{U} / \mathrm{ml}$ for prophylaxis, based on a previous study and international recommendations. ${ }^{14}$ This study was restricted to full term newborn infants less than 2 months of age, who were followed up for two months, and preterm newborn infants less than 37 weeks of gestational age, who were followed up to $37-40$ weeks of gestational age.

\section{Comparison of factors that could potentially influence dosing of enoxaparin}

Newborn infants were subdivided into groups based on: gestational age; need for assisted ventilation and intensive care; CHD; impaired renal and liver function; thrombocytopenia; abnormal coagulation screening test (PT/INR). Previous studies suggest that these factors may affect dosing of $\mathrm{LMMH}^{16}$

\section{Gestational age (two groups)}

The age groups were determined in advance of the analysis: $<37$ weeks; $\geqslant 37$ weeks.

\section{Assisted ventilation and intensive care (three groups)}

Three groups were considered: assisted ventilation with need for intensive care; assisted ventilation not present but need for intensive care; standard care on the ward-that is, no assisted ventilation and no need for intensive care.

\section{CHD (two groups)}

Two categories were considered: newborn infants with CHD; newborn infants without CHD.
Impaired renal and liver function (two groups)

Two categories were considered: newborn infants with impaired renal and liver function; newborn infants with normal renal and liver function.

Thrombocytopenia (two groups)

Two categories were considered: newborn infants with a platelet count $\leqslant 120 \times 10^{9} /$; newborn infants with a platelet count $>120 \times 10^{9} / 1$.

\section{Abnormal coagulation screening test (PT/INR) (two} groups)

Two categories were considered: newborn infants with INR $>1.5$; newborn infants with INR $\leqslant 1.5$

\section{Outcomes by which management of enoxaparin treatment was assessed}

Efficacy of treatment was determined by clot resolution, absence of clot extension, or recurrence established by ultrasonography (US)/echocardiography, venography, or computed tomography.

\section{Treatment outcome variables}

Eight outcome variables were considered in relation to the factors listed above: (a) time taken to achieve the target anti(factor Xa) range; (b) anti-(factor Xa) measurements within target range; (c) anti-(factor Xa) measurements below the target range; (d) anti-(factor Xa) measurements above the target range; (e) mean number of dose changes a month; $(f)$ initial dose; $(g)$ dose required to achieve the target anti-(factor Xa) range; $(h)$ dose to maintain the anti-(factor Xa) level in the target range. Outcome variables $(b)$ to $(d)$ are calculated over the treatment period. Calculated doses to maintain the anti-(factor Xa) level in the target range comprise anti-(factor $\mathrm{Xa})$ doses that resulted in an anti-(factor Xa) level in the target range.

\section{Adverse outcomes}

Bleeding and TEs were considered adverse outcomes. Bleeding was divided into major and minor bleeding. Major bleeding was defined as clinically overt bleeding associated with a decrease of $>20 \mathrm{~g} / \mathrm{l}$ in haemoglobin in less than 24 hours and/or need for transfusion of red blood cells, or any central nervous system or retroperitoneal bleed. Minor bleeding was defined as all other bleeding events not meeting the criteria for a major bleed. Clinically suspected TEs were confirmed by objective radiographic tests including US/echocardiography, venography, lineogram, and computed tomography.

\section{Statistical analysis}

Each continuous measure is summarised by its arithmetic mean and standard deviation (SD), and reported in the tables as mean (SD). Relative frequencies are presented as median (25th/75th centile). For the sake of simplicity, interpretability, and brevity, no data transformations were used to adjust for skewness or control variances. The relation between each outcome measure and the six factors (gestational age, assisted ventilation/neonatal intensive care, congenital heart disease, impaired renal/liver function, thrombocytopenia, and abnormal coagulation screening test) was assessed using an analysis of variance model. As this study is essentially observational in nature and the analysis exploratory, $\mathrm{p}$ values falling below 0.05 were considered to be suggestive of a relation, and reported in this analysis. For the factors with more than two levels, posteriori pairwise comparisons between groups were conducted using Bonferroni correction. A linear interpolation model was used to assess anti-(factor Xa) levels during the treatment period using the observed anti-(factor Xa) measurements. All statistical analyses were performed using SPSS 9.0 . 
Table 1 Basic and clinical data of 62 newborn infants receiving 66 courses of enoxaparin

\begin{tabular}{|c|c|c|c|c|c|}
\hline \multirow[b]{2}{*}{ Predictor } & \multicolumn{2}{|c|}{$\begin{array}{l}\text { No of courses of } \\
\text { enoxaparin }\end{array}$} & \multirow{2}{*}{$\begin{array}{l}\text { Gestational } \\
\text { age (weeks) }\end{array}$} & \multirow{2}{*}{$\begin{array}{l}\text { Birth weight } \\
\text { (g) }\end{array}$} & \multirow{2}{*}{$\begin{array}{l}\text { Length of } \\
\text { treatment (days) }\end{array}$} \\
\hline & One & Two & & & \\
\hline \multicolumn{6}{|l|}{ Anti-(factor $\mathrm{Xa}$ ) range } \\
\hline $0.1-0.3(n=8)$ & 8 & & $38.5(2.7)$ & 3200 (1299) & $21.1(16.6)$ \\
\hline $0.5-1.0(n=54)$ & 50 & 4 & $37.9(3.2)$ & 3072 (943) & $29.7(18.6)$ \\
\hline \multicolumn{6}{|l|}{ Gestational age (weeks) } \\
\hline$<37(n=15)$ & 15 & & $33.5(2.7)$ & $1889(808)$ & $30.5(21.8)$ \\
\hline$\geqslant 37(n=47)$ & 43 & 4 & $39.5(1.3)$ & 3478 (661) & $27.9(17.4)$ \\
\hline$A V+N I C U(n=24)$ & 22 & 2 & $37.4(3.4)$ & $2878(914)$ & $31.3(19.3)$ \\
\hline $\operatorname{NICU}(n=17)$ & 15 & 2 & $37.9(3.7)$ & 3362 (1212) & $22.9(17.2)$ \\
\hline Standard care $(n=21)$ & 21 & & $38.9(2.3)$ & $3094(814)$ & $30.0(18.3)$ \\
\hline $\mathrm{CHD}(n=48)$ & 44 & 4 & $38.7(2.3)$ & 3213 (791) & $29.3(17.6)$ \\
\hline Non-CHD $(n=14)$ & 14 & & $35.6(4.4)$ & 2664 (1397) & $26.1(21.6)$ \\
\hline \multicolumn{6}{|c|}{ Impaired renal/liver function } \\
\hline Yes $(n=12)$ & 12 & 2 & $37.8(2.7)$ & $3132(1014)$ & $29.5(20.8)$ \\
\hline No $(n=48)$ & 46 & 2 & $38.1(3.3)$ & 3074 (978) & $28.3(17.9)$ \\
\hline \multicolumn{6}{|l|}{ Thrombocytopenia } \\
\hline$<120 \times 10^{\circ} / /(\mathrm{n}=40)$ & 38 & 2 & $38.4(3.0)$ & 3133 (949) & $29.5(19.0)$ \\
\hline$\geqslant 120 \times 10^{9} / \mid(n=19)$ & 17 & 2 & $37.3(3.4)$ & 2970 (1081) & $28.4(18.4)$ \\
\hline \multicolumn{6}{|l|}{ Abnormal INR } \\
\hline$>1.5(n=9)$ & 6 & 3 & $37.9(2.1)$ & 2907 (688) & $27.6(14.9)$ \\
\hline$\leqslant 1.5(n=50)$ & 49 & 1 & $38.1(3.3)$ & $3133(1044)$ & $29.4(19.0)$ \\
\hline $\begin{array}{l}\text { Data are reported as } \mathrm{m} \\
\text { course of enoxaparin. } \\
\text { AV, Assisted ventilation } \\
\text { international normalise }\end{array}$ & D). & ents & of children & hildren rece & $\begin{array}{l}\text { nore than one } \\
\text { it; INR, }\end{array}$ \\
\hline
\end{tabular}

\section{RESULTS}

\section{Patient population}

A total of 3420 newborn infants below 2 months of age were admitted to HSC between 1 January 1997 and 31 December 1998. Sixty two consecutive newborn infants (1.8\%) who required anticoagulation were treated with LMMH. The infants received 66 courses of LMMH, for a total of 5.39 patient years. Four infants with CHD received two courses of LMMH. LMMH was stopped and changed to standard heparin for cardiac repair. LMMH was restarted after completion of surgery. All infants received the LMMH enoxaparin. Four infants received a short term course of reviparin (Knoll Pharma, Ludwigshafen, Germany) as part of a dose finding study before initiation of a randomised controlled trial. ${ }^{17}$ Partial results for nine patients are reported elsewhere. ${ }^{14}$ Fifty four $(87 \%)$ infants were treated for secondary prophylaxis for TEs, and eight (13\%) were receiving enoxaparin as primary prophylaxis for the prevention of TEs. The cohort consisted of 42 boys $(68 \%)$ and 20 girls $(32 \%)$. CHD was the primary underlying disorder in 46 (74\%) infants. Other major disorders included prematurity $(\mathrm{n}=15(24 \%))$ and meconium aspiration/respiratory distress syndrome and infection $(\mathrm{n}=5(8 \%))$. Thirty six infants $(58 \%)$ had surgery, usually repair of a congenital malformation of the heart. A total of 424 anti-(factor $\mathrm{Xa}$ ) measurements were performed. Fifty nine infants achieved a minimum of one measurement in the target anti-(factor Xa) range. Three infants (one extremely premature and two term) who were treated for only two days and three days respectively never achieved an anti-(factor Xa) level in the target range. The newborn infants had TEs located in the lower venous system $(n=25)$, upper venous system $(\mathrm{n}=11)$, aorta and other main arteries $(\mathrm{n}=9)$, central nervous system $(n=4)$, heart $(n=3)$, small arteries $(n=1)$, and Blalock-Taussig shunt $(\mathrm{n}=1)$. Thirty seven infants were diagnosed with catheter associated thrombosis: central venous line $(n=16)$, cardiac catheterising procedures $(n=13)$, percutaneous infant central catheter lines $(n=5)$, and umbilical arterial/venous catheters $(n=3)$. The TE completely obstructed blood flow in 23 infants and partly obstructed blood flow in 29; this information was not available for 10 .

\section{Group characteristics}

Table 1 gives the numbers of newborn infants in each of the groups. They were predominantly boys (42:20). There were no significant differences in sex and length of treatment between the groups decided before analysis. Although frequencies across groups are unbalanced, sufficient numbers existed to perform analysis.

\section{Treatment outcome variables}

Table 2 provides a descriptive summary of the outcome measures $(a)$ to $(e)$, and table 3 gives $(f)$ to $(h)$. The results are discussed below.

(a) Time taken to achieve the target anti-(factor $\mathrm{Xa}$ ) range Preterm infants required longer than full term infants to achieve the target range $(p<0.001)$. Newborn infants treated on the neonatal intensive care unit tended to achieve the target range in a shorter time (NS).

(b) Anti-(factor $\mathrm{Xa}$ ) levels within the target range

Although not significant, there was a tendency to fewer anti(factor Xa) measurements within the target range in preterm infants. Infants who received standard care on the ward had fewer anti-(factor Xa) measurements within the target range compared with the other groups (NS).

(c) Anti-(factor $\mathrm{Xa}$ ) measurements below the target range Preterm infants had significantly more anti-(factor Xa) measurements below the target range $(p<0.05)$. Infants who received standard care on the ward had more anti-(factor Xa) measurements below the target range than the other groups (NS). Almost half (48\%) of all anti-(factor Xa) measurements were below the target range.

(d) Anti-(factor $\mathrm{Xa}$ ) measurements above the target range Overall, $2 \%$ of all anti-(factor Xa) measurements were above the target range. Two thirds (67\%) of measurements above the target range occurred in infants with impaired renal/liver function. 
Table 2 Effect of predictors on treatment with enoxaparin

\begin{tabular}{|c|c|c|c|c|c|}
\hline Predictor & $\begin{array}{l}\text { (a) Time taken to } \\
\text { achieve target } \\
\text { anti-(factor Xa) (days) }\end{array}$ & $\begin{array}{l}\text { (b) Anti-(factor Xa) } \\
\text { measurements within } \\
\text { target range (\%) }\end{array}$ & $\begin{array}{l}\text { (c) Anti-(factor Xa) } \\
\text { measurements } \\
<\text { target range }(\%)\end{array}$ & $\begin{array}{l}(d) \text { Anti- }(\text { factor } \mathrm{Xa}) \\
\text { measurements } \\
>\text { target range }(\%)\end{array}$ & $\begin{array}{l}\text { (e) Mean number of } \\
\text { dose changes/month }\end{array}$ \\
\hline \multicolumn{6}{|c|}{ Gestational age (weeks) } \\
\hline$<37$ weeks & $6.0(2.5 / 10.0)$ & $50.0(26.8 / 63.3)$ & $50.0(36.7 / 73.2)$ & $0.0(0.0 / 0.0)$ & $2.2(1.3 / 3.7)$ \\
\hline$\geqslant 37$ weeks & $2.0(1.0 / 6.0)$ & $52.3(33.3 / 75.0)$ & $44.5(25.0 / 66.7)$ & $0.0(0.0 / 0.0)$ & $1.1(0.8 / 2.0)$ \\
\hline $\mathrm{p}$ Value & $<0.001$ & NS & $<0.05$ & NS & NS \\
\hline \multicolumn{6}{|l|}{$\mathrm{AV} / \mathrm{NICU}$} \\
\hline $\mathrm{AV}+\mathrm{NICU}$ & $2.0(1.0 / 6.0)$ & $60.0(37.2 / 75.0)$ & $40.0(25.0 / 51.4)$ & $0.0(0.0 / 0.0)$ & $1.7(0.6 / 2.5)$ \\
\hline $\mathrm{NICU}$ & $2.0(2.0 / 7.0)$ & $57.1(33.3 / 75)$ & $42.9(25.0 / 66.7)$ & $0.0(0.0 / 0.0)$ & $1.7(1.0 / 3.0)$ \\
\hline Standard care & $4.0(1.0 / 10.5)$ & $40.0(33.3 / 61.7)$ & $60.0(38.3 / 66.7)$ & $0.0(0.0 / 0.0)$ & $1.2(0.6 / 2.3)$ \\
\hline $\mathrm{p}$ Value & NS & NS & NS & NS & NS \\
\hline \multicolumn{6}{|l|}{$\mathrm{CHD}$} \\
\hline $\mathrm{CHD}$ & $2.0(1.0 / 7.0)$ & $50.0(33.3 / 75.0)$ & $46.7(25.0 / 66.7)$ & $0.0(0.0 / 0.0)$ & $1.3(0.7 / 2.4)$ \\
\hline Non-CHD & $4.0(2.0 / 6.0)$ & $56.4(32.5 / 65.6)$ & 43.7 (34.4/67.5) & - & $2.0(1.0 / 3.8)$ \\
\hline $\mathrm{p}$ Value & NS & NS & NS & NS & NS \\
\hline \multicolumn{6}{|c|}{ Impaired renal/liver function } \\
\hline Yes & $4.0(1.0 / 10.3)$ & $57.8(33.3 / 75.0)$ & $35.4(25.0 / 58.3)$ & $0.0(0.0 / 8.0)$ & $3.0(2.0 / 4.3)$ \\
\hline No & $2.0(1.5 / 6.0)$ & $50.0(33.3 / 75.0)$ & $50.0(31.0 / 66.7)$ & $0.0(0.0 / 0.0)$ & $1.0(0.6 / 2.0)$ \\
\hline $\mathrm{p}$ Value & NS & NS & NS & NS & $<0.001$ \\
\hline \multicolumn{6}{|l|}{ Thrombocytopenia } \\
\hline$\leqslant 120 \times 10^{9} / 1$ & $2.0(1.0 / 6.5)$ & $50.0(33.3 / 69.1)$ & $50.0(29.7 / 66.7)$ & $0.0(0.0 / 0.0)$ & $1.3(0.8 / 2.7)$ \\
\hline$>120 \times 10^{9} / 1$ & $2.5(1.8 / 7.8)$ & $56.4(33.3 / 75.0)$ & $41.4(25.0 / 58.3)$ & $0.0(0.0 / 0.0)$ & $1.7(1.0 / 2.8)$ \\
\hline $\mathrm{p}$ Value & NS & NS & NS & NS & NS \\
\hline \multicolumn{6}{|c|}{ Abnormal coagulation screening test (PT/INR) } \\
\hline INR $>1.5$ & $2.5(1.3 / 9.3)$ & $57.8(27.8 / 72.9)$ & $42.2(27.1 / 55.6)$ & $0.0(0.0 / 0.0)$ & $1.9(0.7 / 3.3)$ \\
\hline INR $\leqslant 1.5$ & $2.0(1.0 / 6.0)$ & $50.0(33.3 / 71.4)$ & $46.7(27.3 / 66.7)$ & $0.0(0.0 / 0.0)$ & $1.3(1.0 / 2.8)$ \\
\hline $\mathrm{p}$ Value & NS & NS & NS & NS & NS \\
\hline
\end{tabular}

Data are reported as median (25th/75th centile). Significant relations are in bold.

$\mathrm{AV}$, Assisted ventilation; CHD, congenital heart disease; NICU, neonatal intensive care unit; PT, prothrombin time; INR, international normalised ratio.

(e) Mean number of dose changes a month

Infants with impaired renal and liver function required significantly more dose changes a month $(p<0.001)$. Although not significant, preterm infants required more dose changes than full term infants. Newborn infants treated on

Table 3 Effect of predictors on dosing of enoxaparin in $\mathrm{mg} / \mathrm{kg}$ body weight twice a day

\begin{tabular}{|c|c|c|c|}
\hline Predictor & $\begin{array}{l}\text { (f) Initial } \\
\text { dose } \\
(\mathrm{mg} / \mathrm{kg})\end{array}$ & $\begin{array}{l}\text { (g) Dose to } \\
\text { achieve } \\
\text { anti-(factor } \mathrm{Xa} \text { ) } \\
\text { in target range } \\
\text { (mg/kg) }\end{array}$ & $\begin{array}{l}\text { (h) Dose to } \\
\text { maintain } \\
\text { anti-(factor Xa) } \\
\text { in target range } \\
(\mathrm{mg} / \mathrm{kg})\end{array}$ \\
\hline \multicolumn{4}{|c|}{ Gestational age (weeks) } \\
\hline$<37$ weeks & $1.3(0.3)$ & $1.9(0.6)$ & $2.1(0.6)$ \\
\hline$\geqslant 37$ weeks & $1.5(0.4)$ & $1.6(0.3)$ & $1.7(0.3)$ \\
\hline p Value & NS & 0.009 & $<0.001$ \\
\hline \multicolumn{4}{|l|}{$\mathrm{AV} / \mathrm{NICU}:$} \\
\hline$A V+N I C U$ & $1.5(0.3)$ & $1.7(0.4)$ & $1.7(0.4)$ \\
\hline $\mathrm{NICU}$ & $1.5(0.6)$ & $1.6(0.4)$ & $1.9(0.5)$ \\
\hline No & $1.4(0.3)$ & $1.8(0.3)$ & $1.8(0.3)$ \\
\hline $\mathrm{p}$ Value & NS & NS & NS \\
\hline \multicolumn{4}{|l|}{ CHD } \\
\hline $\mathrm{CHD}$ & $1.5(0.4)$ & $1.6(0.3)$ & $1.7(0.3)$ \\
\hline Non-CHD & $1.4(0.3)$ & $1.9(0.5)$ & $2.1(0.6)$ \\
\hline $\mathrm{p}$ Value & NS & 0.03 & $<0.001$ \\
\hline \multicolumn{4}{|c|}{ Impaired renal/liver function } \\
\hline Yes & $1.4(0.6)$ & $1.7(0.5)$ & $1.7(0.6)$ \\
\hline No & $1.5(0.3)$ & $1.7(0.3)$ & $1.8(0.4)$ \\
\hline $\mathrm{p}$ Value & NS & NS & NS \\
\hline \multicolumn{4}{|c|}{ Thrombocytopenia } \\
\hline$\leqslant 120 \times 10^{\circ} / 1$ & $1.4(0.4)$ & $1.7(0.4)$ & $1.8(0.4)$ \\
\hline$>120 \times 10^{9} / 1$ & $1.4(0.3)$ & $1.7(0.4)$ & $1.8(0.6)$ \\
\hline $\mathrm{p}$ Value & NS & NS & NS \\
\hline \multicolumn{4}{|c|}{ Abnormal coagulation screening test (PT/INR) } \\
\hline INR $>1.5$ & $1.6(0.5)$ & $1.7(0.5)$ & $1.7(0.5)$ \\
\hline INR $\leqslant 1.5$ & $1.4(0.4)$ & $1.7(0.4)$ & $1.8(0.4)$ \\
\hline p Value & NS & NS & NS \\
\hline
\end{tabular}

Data are reported as mean (SD). Significant relations are in bold. $\mathrm{AV}$, Assisted ventilation; CHD, congenital heart disease; NICU, neonatal intensive care unit; PT, prothrombin time; INR, international normalised ratio. the neonatal intensive care unit required more dose changes than those who received standard care on the ward (NS). Infants without CHD needed more dose changes than those with CHD (NS). Infants with abnormal coagulation tests required more dose changes than those with PT/INR values in the normal range (NS).

(f) Initial dose

Preterm infants received a lower dose than full term infants (NS).

(g) Dose required to achieve the target anti-(factor $\mathrm{Xa}$ ) range

Preterm infants required a significantly higher dose to achieve the target anti-(factor Xa) range than full term infants $(p=0.009)$. Infants with CHD required a significantly lower dose to achieve the target anti-(factor $\mathrm{Xa}$ ) range than those with other diseases $(p=0.03)$.

(h) Dose to maintain anti-(factor $\mathrm{Xa}$ ) level in the target range

Preterm infants required significantly more enoxaparin to maintain the anti-(factor Xa) level in the target range than full term infants $(p<0.001)$. Infants with $\mathrm{CHD}$ required a significantly lower dose to maintain the anti-(factor Xa) level in the target range $(\mathrm{p}<0.001)$.

\section{Efficacy of enoxaparin}

Complete or partial resolution of TE was achieved in 59\% of newborn infants. Complete resolution of the thrombus was accomplished in 15. Four of these had shown complete obstruction of blood flow measured by Doppler US or echocardiography before treatment.

\section{Adverse outcomes}

All newborn infants were followed for a minimum of three months or until completion of the course of treatment.

\section{Bleeding}

Serious bleeding occurred in four infants, giving an overall incidence of $1.2 \%$ per patient year. Newborn infants were 
receiving enoxaparin for secondary prophylaxis. Two developed major bleeding at the site at which enoxaparin was administered through a small plastic SQ catheter (insuflon; Viggo, Lynge, Denmark). One infant with severe malformation of the heart acquired a small intracerebral haemorrhage three days after initiation of enoxaparin treatment. Another infant was diagnosed with haemorrhagic infarction following sinovenous thrombosis shortly after cardiac arrest during major cardiac surgery. Four infants developed minor bleeding: haematuria, bloody stool, and bleeding at the local enoxaparin administration site. Bleeding never occurred when the anti-(factor Xa) level was above the target range. None of the bleeding episodes resulted in severe sequelae or death.

\section{Thrombotic events}

TEs occurred in three newborn infants with CHD, giving an overall incidence of $0.9 \%$ per patient year. Two showed extension of thrombi during enoxaparin treatment although concomitant treatment with acetylsalicylic acid was administered. One of these infants died from thrombotic obstruction of the modified Blalock-Taussig shunt. Another who had extracorporeal membrane oxygenation developed a stroke. One more infant with CHD and renal failure due to thromboembolic occlusion of the renal veins experienced an extensive TE five days after the end of enoxaparin treatment. Thrombectomy before initiation of enoxaparin was performed in two infants. One developed signs of post-thrombotic syndrome during the follow up period.

In summary, six children died before completion of their first year of life. One died from clot extension, and another three died shortly after major cardiac surgery. One preterm infant died before 11 months of age from lung, liver, and gut failure. The actual cause of death of another infant with severe malformation of the heart, renal failure, and clot extension is not entirely clear.

\section{DISCUSSION}

The purpose of this study was to evaluate enoxaparin treatment in newborn infants. A non-selected consecutive cohort of 62 newborn infants receiving 66 courses of enoxaparin in the first few months of life was prospectively studied. The study database comprises a total of 5.39 patient years of enoxaparin treatment and was analysed for many factors that could potentially influence clinical management of enoxaparin treatment.

Management of newborn infants with TE is controversial. Although most newborn infants who receive only supportive care for TE survive, their morbidity is substantial. ${ }^{1}$ Therefore more aggressive treatment with heparin anticoagulation has been introduced despite the absence of well designed studies documenting its efficacy and safety. We present the largest report on an unselected cohort of preterm and full term newborn infants treated with the LMMH enoxaparin in the first few months of life. Newborn infants with CHD are probably overrepresented compared with other paediatric hospitals because most cardiac surgery in Ontario is performed at HSC. In contrast with most paediatric hospitals, an anticoagulation service provided consistent support for testing and dosing of enoxaparin.

All newborn infants presented with severe underlying conditions. TEs occurred predominantly in the lower and upper venous system and main arteries associated with indwelling catheters. This supports previous work carried out by the Canadian Childhood Thrombophilia Registry which showed the adverse influence of venous and arterial lines on the development of TE. ${ }^{1}$ Low cardiac output combined with low systolic blood pressure in newborn infants with malformation of the heart, persistent fetal circulation in the severely ill preterm infant, and an inverse catheter/vessel diameter relation may contribute to this finding.

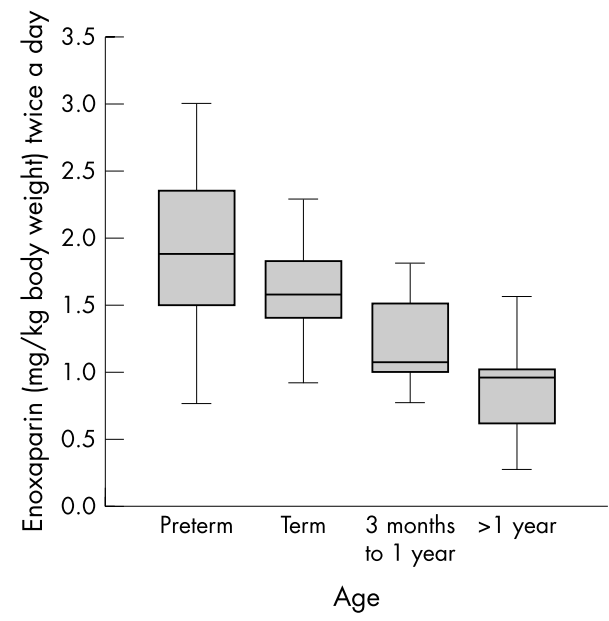

Figure 1 Effect of gestational age on the dose of enoxaparin required to maintain the anti-(factor $\mathrm{Xa}$ ) level in the target range of $0.5-1.0 \mathrm{U} / \mathrm{ml}$. Preterm newborn infants required more enoxaparin than full term newborn infants and older children. Data from older children are published elsewhere. ${ }^{14}$

In contrast with adults, monitoring of LMMH in newborn infants and throughout childhood is mandatory for several reasons. Newborn infants gain weight and grow quickly; therefore the dose to achieve a target anti-(factor Xa) level needs to be constantly recalculated. Newborn infants often have serious conditions that put them at a higher risk of bleeding (thrombocytopenia and renal failure resulting in decreased clearance of enoxaparin and liver impairment with decreased synthesis of clotting/fibrinolytic factors and vitamin $\mathrm{K}$ deficiency). In this study, a mean of seven anti-(factor Xa) tests per newborn infant was performed. Almost all infants achieved an anti-(factor Xa) level in the target range. In contrast with anticoagulation of older children and adults, newborn infants did not show anti-(factor Xa) levels consistently in the target range. Some $2 \%$ of anti-(factor Xa) levels were above the upper limit of the target range. Half of all anti(factor Xa) measurements were in the target anti-(factor Xa) range of $0.5-1.0 \mathrm{U} / \mathrm{ml}$. The treatment of preterm newborns was complicated by the length of time required to achieve an anti-(factor $\mathrm{Xa}$ ) level in the target range and the higher doses of enoxaparin required to achieve and maintain the anti(factor Xa) level in the target range. This is the first time that it has been shown that preterm infants need more enoxaparin than full term infants and older children (fig 1). CHD significantly influenced enoxaparin dosing; specific age related features of CHD, heart failure with low cardiac output, liver congestion, and associated renal failure may explain at least in part this finding. Impaired hepatic and renal function resulted in more dose changes a month. In this study, better bioavailibility and dose independent clearance and decreased affinity for heparin binding proteins did not reduce the need for monitoring of enoxaparin treatment. However, with its apparent half life of three to four hours, administering enoxaparin twice a day was convenient and effective.

We found that, with careful monitoring and laboratory evidence of therapeutic enoxaparin effect, in 59\% of newborn infants, complete or partial resolution of the TE was achieved, confirmed by US/echocardiography, venography/lineogram, or computed tomography. Complete resolution of the thrombus was accomplished in 15 infants. This effect was independent of complete or partial obstruction of blood flow. Previous reports of treatment of TE at various locations with standard heparin showed only a poor response, which may at least in part be explained by the late initiation of treatment and inadequate testing. ${ }^{25}$

LMMHs may cause less bleeding for several reasons. Firstly, LMMH inhibits platelet function less than standard heparin 
because standard heparin binds to platelets. Secondly, unlike standard heparin, LMMH does not increase microvascular permeability. Thirdly, LMMH is less likely to interfere with interaction between platelets and vessel walls. However, preterm newborn infants and full term newborn infants with severe underlying conditions are at particular risk of bleeding. Predisposing factors include immaturity of the vascular system, liver disease and vitamin K deficiency, sepsis and disseminated intravascular coagulation, and treatment related factors. In our cohort, enoxaparin was associated with a similar risk of bleeding to that in older children and adults. The incidence of major bleeding is $1.6 \%$ in adult medical patients treated with enoxaparin. ${ }^{18}$ We observed an incidence of $1.2 \%$ in our cohort. Bleeding occurred predominantly at the site of administration. The use of the insuflon, a newly developed device consisting of a patch and thin plastic catheter with its tip placed subcutaneously, through which enoxaparin could be administered painlessly, may have contributed to this finding. However, the insuflon facilitated routine care and was successfully used in most patients of this cohort. As some authors believe that bleeding due to administration of LMMH may be delayed for up to three weeks after discontinuation of LMMH, the incidence of bleeding may be even higher. ${ }^{5}$

There was evidence of clot extension and recurrence of TE in three newborn infants in our cohort. One died from thrombotic occlusion of the Blalock-Taussig shunt. The anti-(factor $\mathrm{Xa})$ level was in the target range when complete shunt occlusion occurred. There are no studies available comparing the efficacy of standard heparin with LMMH in children presenting with TE.

Heparin induced thrombocytopenia, which can cause devastating thrombotic complications, is triggered by antibodies directed against complexes of heparin and platelet factor 4, which form on the surface of platelets and activate their Fc receptors. In recent trials in adults, the incidence of heparin induced thrombocytopenia was significantly lower in patients given LMMH than in those receiving standard heparin. ${ }^{13}$ There are few reports on the development of heparin induced thrombocytopenia in newborn infants, although severe thrombocytopenia is a common observation during the treatment of critically ill newborn infants. ${ }^{11}{ }^{19-21}$ Although several newborn infants have been tested for the presence of heparin induced thrombocytopenia, testing was negative in all cases.

When given for more than one month, standard heparin can cause osteoporosis. ${ }^{12}$ In an in vitro cell model using animal bone cells and in case series, the osteoclastic process and incidence of osteoporosis was lower when LMMH was administered compared with standard heparin. ${ }^{22}$ However, bone fractures resulting from osteopenia is a common observation in the critically ill newborn infant depending on the length of illness, severity of disease, and drugs administered. We did not screen for osteoporosis in our cohort.

In conclusion, administration of enoxaparin in newborn infants appears to be an acceptable alternative to treatment with standard heparin or no treatment with anticoagulants at all, as TEs in the newborn infant often have severe sequelae. Preterm infants are more difficult to treat than full term infants. This trend persists beyond the neonatal period throughout childhood. ${ }^{14}{ }^{23}$ Enoxaparin was associated with a relatively low risk of bleeding in our cohort.

Further studies to improve outcome and reduce adverse effects of anticoagulation treatment should address: introduction of screening tests in high risk newborn infants to decide on prophylactic anticoagulation and provide early onset treatment; investigation of appropriate dosing of $\mathrm{LMMH}$ in preterm and full term infants; development and testing of new anticoagulant drugs that, in contrast with standard heparin and $\mathrm{LMMH}$, are able to inactivate thrombin bound to fibrin, which may be an important trigger for clot extension at sites of vascular injury.

\section{ACKNOWLEDGEMENTS}

This work was supported by an award from the Austrian Pediatric Society 2000. AKCC is the recipient of a research scholarship from the Heart and Stroke Foundation of Canada.

\section{Authors' affiliations}

W Streif, Department of Pediatrics, University of Innsbruck, Austria

G Goebel, Department of Biostatistics and Documentation, University of Innsbruck

A K C Chan, Department of Pediatrics, McMaster University, Hamilton, Canada

M P Massicotte, The Hospital for Sick Children, Toronto, Canada

\section{REFERENCES}

1 Monagle $\mathbf{P}$, Adams M, Mahoney $M$, et al. Outcome of pediatric thromboembolic disease: a report from the Canadian Childhood Thrombophilia Registry. Pediatr Res 2000:47:763-6.

2 Monagle $\mathbf{P}$, Michelson AD, Bovill E, et al. Antithrombotic therapy in children. Chest 2001;119:344S-70S.

3 Andrew M, Paes B, Milner R, et al. Development of the human coagulation system in the healthy premature infant. Blood 1988;72:1651-7.

4 Andrew M, Paes B, Milner R, et al. Development of the human coagulation system in the full-term infant. Blood 1987;70:165-72.

5 Massicotte MP. Low-molecular-weight heparin therapy in children. J Pediatr Hematol Oncol 2001;23:189-94.

6 Sutor AH, Massicotte $\mathrm{P}$, Leaker $M$, et al. Heparin therapy in pediatric patients. Semin Thromb Hemost 1997;23:303-19.

7 Ankola PA, Atakent YS. Effect of adding heparin in very low concentration to the infusate to prolong the patency of umbilical artery catheters. Am J Perinatol 1993;10:229-32.

8 Horgan MJ, Bartoletti A, Polansky S, et al. Effect of heparin infusates in umbilical arterial catheters on frequency of thrombotic complications. J Pediatr 1987;111:774-8.

9 Freed MD, Keane JF, Rosenthal A. The use of heparinization to prevent arterial thrombosis after percutaneous cardiac catheterization in children. Circulation 1974:50:565-9.

10 Saxena A, Gupta R, Kumar RK, et al. Predictors of arterial thrombosis after diagnostic cardiac catheterization in infants and children randomized to two heparin dosages. Cathet Cardiovasc Diagn 1997:41:400-3.

11 Severin T, Sutor AH. Heparin-induced thrombocytopenia in pediatrics. Semin Thromb Hemost 2001;27:293-9.

12 Muir JM, Andrew M, Hirsh J, et al. Histomorphometric analysis of the effects of standard heparin on trabecular bone in vivo. Blood 1996:88:1314-20.

13 Hirsh J, Warkentin TE, Shaughnessy SG, et al. Heparin and low-molecular-weight heparin: mechanisms of action, pharmacokinetics, dosing, monitoring, efficacy, and safety. Chest 2001;1 19:64S-94S

14 Dix D, Andrew M, Marzinotto V, et al. The use of low molecular weight heparin in pediatric patients: a prospective cohort study. J.Pediatr 2000; 136:439-45.

15 Andrew M, Michelson AD, Bovill E, et al. Guidelines for antithrombotic therapy in pediatric patients. J Pediatr 1998;132:575-88.

16 Streif W, Mitchell LG, Andrew M. Antithrombotic therapy in children. Curr Opin Pediatr 1999;1 1:56-64.

17 Massicotte $\mathbf{P}$, Julian JA, Gent $M$, et al. An open-label randomized controlled trial of low molecular weight heparin for the prevention of central venous line related thrombotic complications in children: the PROTEKT trial [abstract]. Thromb Haemost 2001; OC970(suppl).

18 Levine MN, Raskob G, Landefeld S, et al. Hemorrhagic complications of anticoagulant treatment. Chest 1998;114:511S-23S.

19 Spadone D, Clark F, James E, et al. Heparin-induced thrombocytopenia in the newborn. J Vasc Surg 1992;15:306-1 1.

20 Zohrer B, Zenz W, Rettenbacher A, et al. Danaparoid sodium (Orgaran) in four children with heparin-induced thrombocytopenia type II. Acta Paediatr 2001:90:765-71.

21 Saxon BR, Black MD, Edgell D, et al. Pediatric heparin-induced thrombocytopenia: management with Danaparoid (orgaran). Ann Thorac Surg 1999;68:1076-8.

22 Muir JM, Hirsh J, Weitz Jl, et al. A histomorphometric comparison of the effects of heparin and low-molecular-weight heparin on cancellous bone in rats. Blood 1997;89:3236-42.

23 Punzalan RC, Hillery CA, Montgomery RR, et al. Low-molecular-weight heparin in thrombotic disease in children and adolescents. J Pediatr Hematol Oncol 2000;22:137-42. 